\title{
A retrospective comparative analysis of elderly and younger patients undergoing pulmonary resection for stage I non-small cell lung cancer
}

Byungjoon Park, Genehee Lee, Hong Kwan Kim, Yong Soo Choi, Jae II Zo, Young Mog Shim and Jhingook Kim*

\begin{abstract}
Background: Age has been a critical predictor for immediate postoperative and long-term results after the pulmonary resection for lung cancer. In this study, we evaluated and compared surgical outcome of stage I non-small cell lung cancer and associated predictive factors between elderly and younger groups.

Methods: Short- and long-term outcomes of elderly group ( $\geq 70$ years) who were surgically treated and pathologically diagnosed as stage I non-small cell lung cancer from 2004 to 2010 were compared to the results of younger group ( $<70$ years).

Results: Total of 1340 patients were included in this study, and the patients were divided into the elderly group $(n=285)$ and the younger group $(n=1055)$. The proportions of squamous cell carcinoma (36.8 vs. $20.0 \%, p<0.001)$ and stage IB cancer (58.3 vs. $40.6 \%, p<0.001$ ) were significantly higher in the elderly group than the younger group. The 30-day and 90 -day mortalities were significantly higher in the elderly group ( 1.8 vs. $0 \% ; p=0.014,3.9$ vs. $0.5 \% ; p<0.001$, respectively). The elderly patients also had significantly worse long-term outcomes than the younger group (5-year overall survival rate, 69.0 vs. $91.1 \%$; $p<0.001,5$-year disease-free survival rate, 53.3 vs. $80.2 \% ; p<0.001$ ). Decreased diffusion capacity less than $70 \%$ was an important predictive factor for short- and long-term outcomes in both the younger and the elderly group.

Conclusions: Elderly patients with low diffusion capacity are at risk for significantly worse outcome, indicating that patient selection should include assessment of pulmonary function, including diffusion capacity.
\end{abstract}

Keywords: Lung cancer, Surgery, Geriatric, Pulmonary function

\section{Background}

Lung cancer is a dreadful disease, but better results can be obtained with early detection and effective surgery. Accordingly, considerable effort has been devoted to early diagnosis of lung cancer. Lung cancer is the second most common cancer for those aged 70 years or older, and the likelihood of developing new lung cancer was 1 in 15 for males and 1 in 20 for females in the USA in 2013 [1]. Rapid expansion of the geriatric population in both developed and developing countries has increased the number of cases of newly diagnosed lung cancer in

\footnotetext{
* Correspondence: jkimsmc@skku.edu

Department of Thoracic and Cardiovascular Surgery, Samsung Medical

Center, Sungkyunkwan University School of Medicine, 81 Irwon-ro,

Gangnam-gu, Seoul 135-710, South Korea
}

elderly patients, and lung cancer has literally become a "disease of elderly people" [2].

However, surgical treatment, the gold standard in early lung cancer, is not always recommended for elderly patients compared to younger patients. According to the previous studies, only less than $50 \%$ of patients older than 75 years were rendered to undergo surgical resection even for early non-small cell lung cancer (NSCLC) for a variety of reasons, including comorbidities and personal decisions not to pursue further treatment $[3,4]$. On the other hand, a few encouraging results of successful surgery in octogenarians or nonagenarians with early lung cancer have been reported [5-7]. Even so, most existing studies were conducted in highly selected patient populations and focused mainly on early outcomes, 
making them insufficient to justify recommending for or against surgery in elderly patients in general.

To confirm that pulmonary resections in elderly patients are as safe as in younger patients, it is important to compare surgical outcomes and also associated predictors. Furthermore, if elderly patients show worse outcomes, it is important to identify not only common predictive factors in both age groups but also age-specific factors, and this would be helpful to establish more elderly-specific guideline for selecting surgery patients. In this study, we evaluated and compared short- and long-term outcomes of elderly and younger patients who underwent pulmonary resection for stage I NSCLC and analyzed common predictive factors and specific factors for both age groups.

\section{Methods}

\section{Patients and data collection}

This was a retrospective observational study performed in a single center and approved by the hospital's institutional review board. From January 2004 to December 2010, 3033 patients were surgically treated with curative intent for primary lung cancer, and 1787 patients were pathologically diagnosed with stage I NSCLC. Patients with synchronous double primary lung cancer $(n=49)$, previous history of other malignancy $(n=162)$ and those without mediastinal lymph node dissection $(n=145)$ were excluded from the study. Patients with histologic subtypes other than adenocarcinoma, squamous cell carcinoma, or large cell neuroendocrine carcinoma were also excluded $(n=107)$.

A total of 1340 patients were enrolled, with 285 patients $(21.3 \%)$ in the elderly group ( $\geq 70$ years) and 1055 patients $(78.7 \%)$ in the younger group ( $<70$ years). Significant cutoff value of age groups by 5 years for 30-day mortality and overall survival was analyzed by a minimal $p$ value approach. Data on clinical, surgical, and pathologic characteristics were collected. Preoperative pulmonary function tests included forced expiratory volume in 1 second $\left(\mathrm{FEV}_{1}\right)$, forced vital capacity $(\mathrm{FVC}), \mathrm{FEV}_{1} / \mathrm{FVC}$, percentile expected $\mathrm{FEV}_{1}$, percentile expected $\mathrm{FVC}$, diffusing capacity for carbon monoxide (DLCO), and percentile expected DLCO. Laboratory data including liver and kidney function tests and ejection fraction from preoperative echocardiography were also collected. The type of operation and extent of pulmonary resection were included as surgical factors.

\section{Surgical procedures and follow-up}

The standard treatment for stage I NSCLC was lobectomy or bi-lobectomy, in patients with limited pulmonary function or severe emphysema, segmentectomy or wedge resection was performed. After surgery, 4 patients (1.4\%) from elderly group and 16 patients (1.5\%) from younger group underwent adjuvant chemotherapy. The patients visited the outpatient clinic and underwent computed tomography or positron emission tomography/computed tomography every 3 months for 2 years after the surgery and then every 6 months for the next 3 years. The patients visited the hospital annually after 5 years from the initial operation. The median follow-up period was 47.6 months.

Patient survival was reviewed, and the end date was defined as the date of latest follow-up or death. The disease-free survival period was defined as the interval from surgery to the first interpretation of recurrence in an imaging study. Cancer recurrence was defined as carcinoma recurring in the lung or a distant organ and was classified as loco-regional failure or distant failure according to the initial site of recurrence. In detail, local failure was defined as disease recurrence at the surgical resection margin, regional failure as tumor recurrence in the mediastinal, hilar, or supraclavicular lymph nodes, and lung cancer in the ipsilateral lung, pleura, or chest wall. Distant failure was defined as lung cancer other than loco-regional failure or cancer metastasis in a distant organ. Metachronous double primary cancer was defined according to modified Martini's criteria and was excluded from cancer recurrence. Newly appeared pure ground glass opacity in the ipsilateral lung within 2 years was also excluded from cancer recurrence.

The date of death for patients who expired during the follow-up period was confirmed by our hospital $(n=64)$ or National Cancer Registration Statistics $(n=89)$. Living patients were followed-up in an outpatient clinic $(n=$ $1163)$ or by telephone interview $(n=24)$ within 1 year of data collection.

\section{Statistical analyses}

All data were statistically analyzed using STATA version 10 (2007, Stata Statistical Software: release 10; StataCorp LP, College Station, TX). Ninety-five percent confidence intervals corresponding to a $5 \%$ significance level were used. Mean values were compared using a Student $t$ test and median values by the Wilcoxon signed-rank test. Data were interpreted in two categories. Short-term results, including 30-day and 90-day mortality, hospital stay, in-hospital complication rate, and associated risk factors, were evaluated by logistic regression model, and there were no censored data during the follow-up period of 90 days. Long-term results, including 5-year overall and 5-year disease-free survival and 3-year cumulative recurrence rate, were analyzed with Kaplan-Meier and log-rank tests. Subgroup analyses for risk factors and prognostic factors were evaluated in the elderly group using Cox hazard modeling. For multivariate analyses, backward selection of variables was performed. Variables with significance level $>0.1$ were eliminated from the methods. 


\section{Results}

\section{Patient characteristics}

Median age of elderly group was 73 years (70-86) and of younger group was 58 years (20-69). Male predominance $(p=0.003)$ and the proportions of squamous cell carcinoma (36.8 \% vs. $20.0 \%, p<0.001)$ and stage IB cancer (58.3 vs. $40.6 \%, p<0.001$ ) were significantly higher in the elderly group than the younger group. There was no significant difference in extent of pulmonary resection between the two groups, but open thoracotomy was more frequently performed in elderly patients ( 55.4 vs. $37.8 \%$, $p<0.001)$. Comparison of clinicopathologic features and surgical procedures were demonstrated in Table 1.

\section{Short-term results}

The 30-day mortality rate was 6 of 1340 patients $(0.4 \%)$, and all were elderly. Five patients died of acute respiratory distress syndrome (ARDS) and one from postoperative pneumonia. The only independent factor for 30-day mortality in the elderly group was DLCO less than $70 \%$ of prediction (low DLCO; odd ratio $(\mathrm{OR})=17.1, p=$ 0.024). Mortality within 90 days occurred for 16 patients $(1.2 \%)$ and was significantly more frequent in the elderly group (3.9 vs. $0.5 \%, p<0.001$ ). Independent risk factors for 90-day mortality included being elderly (OR $=2.0, p=$ $0.042)$ and low DLCO $(\mathrm{OR}=3.9, p<0.001)$. The elderly group had significantly longer hospital stays (11.2 vs. 8.0 days, $p<0.001)$. The in-hospital complication rate was also significantly higher in elderly patients (47.7 vs. $26.9 \%$, $p<0.001)$. The most common major complications in the elderly group were new onset of arrhythmia requiring medicine $(16.3 \%)$ and acute lung injury or ARDS (5.7\%), and independent risk factors were low DLCO $(\mathrm{OR}=3.5$, $p=0.045)$ and male gender $(\mathrm{OR}=7.8, p<0.001)$.

\section{Long-term results}

Undoubtedly, elderly patients had significantly worse long-term outcomes than the younger group (5-year overall survival rate; 69.0 vs. $91.1 \%, p<0.001$, Fig. 1). Even so, the difference between the two groups was much larger than expected. In the multivariate analysis, independent prognostic factors for overall survival after pulmonary resection of stage I NSCLC included elderly age (hazard ratio $(\mathrm{HR})=3.6, p<0.001)$, male gender $(\mathrm{HR}=3.2, p=$ 0.005 ), interstitial pulmonary fibrosis (IPF; $\mathrm{HR}=4.8, p<$ $0.001)$, and low DLCO (HR $=3.8, p<0.001)$. Prognostic factors for overall survival were summarized in Table 2 . For the subgroup analysis in the elderly group, independent prognostic factors for overall survival included histologic subtype of squamous cell carcinoma $(\mathrm{HR}=$ $3.2, p=0.001)$ and low DLCO (HR $=2.4, p=0.028)$. On the other hand, independent prognostic factors for overall survival in the younger group were low DLCO $(\mathrm{HR}=5.3, p=0.004)$, male gender $(\mathrm{HR}=5.3, p=0.026)$, and IPF $(\mathrm{HR}=14.1, p<0.001)$.

Disease-free survival showed unexpectedly discouraging results for the elderly group (5-year disease-free survival rate; 53.3 vs. $80.2 \%, p<0.001)$. In the multivariate analysis, independent prognostic factors for diseasefree survival were elderly age $(\mathrm{HR}=2.4, p<0.001)$, male

Table 1 Patient clinicopathologic features and surgical procedures

\begin{tabular}{|c|c|c|c|}
\hline & Elderly group $(n=285)$ & Younger group $(n=1055)$ & $p$ \\
\hline Median age, years (range) & $73(70-86)$ & $58(20-69)$ & $<0.001^{*}$ \\
\hline Sex, male, $n(\%)$ & $201(70.5)$ & $642(60.9)$ & $0.003^{* *}$ \\
\hline Pathologic stage, $n(\%)$ & & & $<0.001^{* *}$ \\
\hline Stage IA & $119(41.7)$ & $527(59.4)$ & \\
\hline Stage IB & $166(58.3)$ & $428(40.6)$ & \\
\hline Histologic subtype, $n(\%)$ & & & $<0.001^{* *}$ \\
\hline Adenocarcinoma & $171(60)$ & $824(78.1)$ & \\
\hline Squamous cell carcinoma & $105(36.8)$ & $211(20)$ & \\
\hline Large cell neuroendocrine carcinoma & $9(3.2)$ & $20(1.9)$ & \\
\hline Extent of resection, $n(\%)$ & & & $0.280^{* *}$ \\
\hline Sublobar resection & $23(8.1)$ & $82(7.8)$ & \\
\hline Lobectomy & $250(87.7)$ & $947(89.7)$ & \\
\hline Bilobectomy & $12(4.2)$ & $26(2.5)$ & \\
\hline Type of operation, $n$ (\%) & & & $<0.001^{* *}$ \\
\hline Video-assisted thoracoscopic surgery & $127(44.6)$ & $656(62.2)$ & \\
\hline Thoracotomy & $158(55.4)$ & $399(37.8)$ & \\
\hline
\end{tabular}

${ }^{*} p$ value estimated by the Wilcoxon signed-rank test

${ }^{* *} p$ value estimated by Pearson's chi-square test 


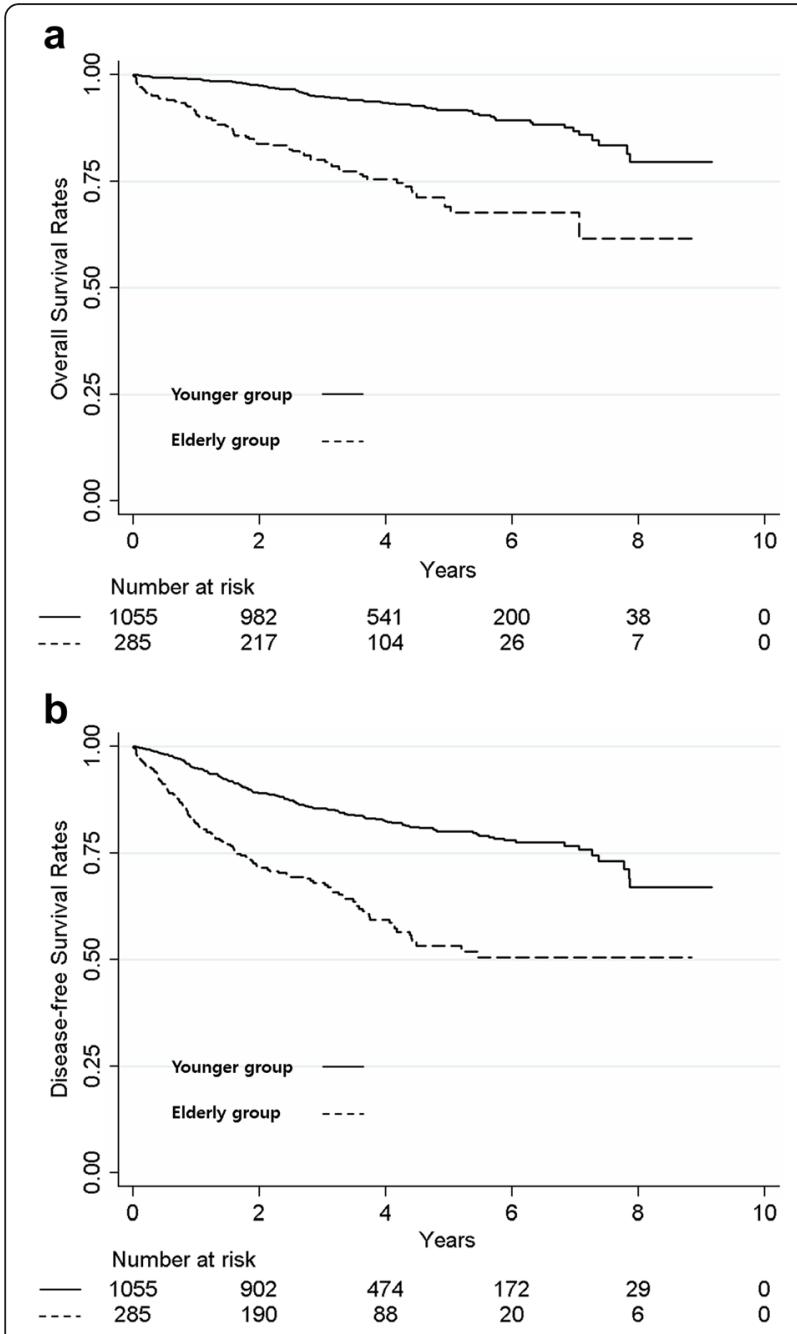

Fig. 1 Kaplan-Meier curve of overall and disease-free survival in younger and elderly groups. a Five-year overall survival rates in the younger and elderly groups were 91.1 and $69.0 \%$, respectively. b Five-year disease-free survival rates in the younger and elderly groups were 80.2 and $49.3 \%$, respectively

gender $(\mathrm{HR}=1.7, p=0.017)$, IPF $(\mathrm{HR}=4.0, p<0.001)$, low DLCO $(\mathrm{HR}=2.0, p=0.006)$, and stage IB $(\mathrm{HR}=2.1$, $p<0.001)$. In the subgroup analysis, independent prognostic factors for disease-free survival in elderly patients were male gender $(\mathrm{HR}=2.6, p=0.007)$ and low DLCO $(\mathrm{HR}=2.1, p=0.03)$. Incidence of recurrence within 2 years was also significantly higher in elderly group than in younger group $(13.7$ vs. $5.7 \%, p<0.001)$. Independent risk factors for recurrence were elderly age $(\mathrm{HR}=3.4, p=0.001)$ and pathologic stage IB over IA $(\mathrm{HR}=4.3, p<0.001)$. Short- and long-term outcomes of stage I lung cancer according to the age group were summarized in Table 3, and results of multivariate analysis in elderly group were also demonstrated in Table 4.

To rule out the effect of functional and pathologic differences other than age between two groups, further pair matching analysis was performed for this unexpected high incidence of recurrence rate in elderly patients. Pair matching analysis was performed by propensity score matching, and 285 pairs of elderly and younger patients were matched 1:1. The clinical variables used for matching were gender, comorbidities, preoperative labs, and pulmonary function tests. Pathologic variables were also matched and included cancer stage and histologic subtype. The surgical variables included extent of pulmonary resection and type of operation.

Analysis of the cumulative recurrence rate after pulmonary resection between the elderly and the matched younger controls to evaluate lung cancer-specific longterm outcome still showed discouraging results for the elderly group. Five-year overall survival rates in the unmatched younger, matched younger, and elderly groups were 91.1, 89.5, and $69.0 \%$, respectively. Five-year diseasefree survival rates in the younger and elderly groups were $80.2 \%, 75.0 \%$ and $53.3 \%$, respectively. Three-year cumulative recurrence rates of the younger and elderly groups were 16.0 and $23.2 \%$, respectively $(p=0.001)$, and stage IB $(\mathrm{HR}=1.7, p=0.035)$ was the only independent risk factor in elderly patients. However, there was no significant difference between the younger group and the elderly group in loco-regional recurrence rate $(11.0$ vs. $11.3 \%, p=$ $0.586)$. Only distant recurrence rate was significantly different between the younger group and the elderly group (5.6 vs. $13.4 \%, p<0.001)$. The most common extrathoracic sites of distant recurrence were brain $(n=15)$, liver $(n=10)$, and bone $(n=10)$, for which the incidence of metastasis was significantly higher in the elderly group (3.5 vs. $8.8 \%, p=0.009$ ). Comparison of elderly patients and matched younger control was demonstrated in supplementary data.

\section{Discussion}

Several large population studies have examined early results after pulmonary resection in elderly patients and reported that the early mortality among elderly patients was significantly greater [8-10]. In a recent study based on a large French national database performed by Rivera et al., postoperative mortality was significantly higher in elderly patients at every end point compared with younger controls (30-day mortality; 3.6 vs. $2.2 \%, p=0.010$, 90-day mortality; 4.7 vs. $2.5 \%, p<0.001$ ), and the authors pointed out that the 90-day mortality rate seems to better represent real mortality risk than the 30-day mortality rate [11], which was supported by our data (30-day mortality; $p=0.014,90$-day mortality; $p<0.001$, Table 3). On the other hand, Cerfolio and colleagues reported in their nested case-control study that there was no significant difference in 30-day or in-hospital mortality between younger and elderly patients ( 3.8 vs. $2.2 \%$, $p=0.20$ ) [12]. However, the proportion of male patients 
Table 2 Prognostic factors for overall survival

\begin{tabular}{|c|c|c|c|c|}
\hline \multirow[b]{2}{*}{ Prognostic factors } & \multicolumn{2}{|c|}{ Univariate analysis (log-rank test) } & \multicolumn{2}{|c|}{ Multivariate analysis (Cox hazard model) } \\
\hline & $\mathrm{HR}(95 \% \mathrm{Cl})$ & $p$ & $\mathrm{HR}(95 \% \mathrm{Cl})$ & $p$ \\
\hline Age group & $4.2(3.1-5.6)$ & $<0.001$ & $3.6(2.1-6.2)$ & $<0.001$ \\
\hline Low DLCO & $5.2(3.2-8.7)$ & $<0.001$ & $3.8(2.1-7.1)$ & $<0.001$ \\
\hline $\mathrm{IPF}^{\mathrm{b}}$ & $13.8(7.6-25.0)$ & $<0.001$ & $4.8(2.1-10.8)$ & $<0.001$ \\
\hline Male & $2.6(1.7-3.9)$ & $<0.001$ & $3.2(1.4-7.1)$ & 0.005 \\
\hline Pulmonary Tbc. $^{c}$ & $1.5(1.1-2.2)$ & 0.039 & & - \\
\hline Hypertension & $1.39(1.1-1.9)$ & 0.036 & & - \\
\hline Diabetes mellitus & $1.9(1.3-2.8)$ & $<0.001$ & & - \\
\hline Decreased kidney function ${ }^{d}$ & $2.7(1.1-7.2)$ & 0.043 & & - \\
\hline Stage IB & $1.9(1.4-2.6)$ & $<0.001$ & & - \\
\hline Lobectomy/bi-lobectomy & $1.7(1.1-2.8)$ & 0.033 & & - \\
\hline Thoracotomy & $2.8(2.0-3.9)$ & $<0.001$ & & - \\
\hline
\end{tabular}

${ }^{a}$ Expected diffusing capacity for carbon monoxide less than $70 \%$ of prediction

${ }^{b}$ Interstitial pulmonary fibrosis

'Previous history of pulmonary tuberculosis

${ }^{\mathrm{d}}$ Preoperative creatinine level higher than $1.5 \mathrm{mg} / \mathrm{dL}$

was significantly lower in their elderly group after matching, and other comorbidities that might be associated with early outcome in elderly patients were not included as matching variables. Recently, Rueth et al. reported that male gender, higher comorbidity index and age older than 75 years significantly increased postoperative mortality [13]. These discouraging results of elderly group might have been caused by the fragility involved with aging process. Fragility, which is often defined as unintentional weight loss, self-reported exhaustion, muscular weakness, slow walking speed, and low physical activity, is identified as an independent risk factor for major morbidity, mortality, protracted length of stay, and institutional discharge $[14,15]$.

To compare long-term outcome, Sigel et al. analyzed 27,859 cases of stage I NSCLC from surveillance, epidemiology, and end results (SEER) data and showed that the overall 5-year survival rate declined slightly with increasing age in male patients who underwent surgical resection (age groups $<60,61-69,70-79, \geq 80 ; 69.2,66.0$,
62.8 , and $63.5 \%$, respectively) but remained similar across all ages [16]. Cerfolio and colleagues reported that 5 -year overall survival in their elderly group ( $\geq 70$ years) was $78 \%$, which was surprisingly better than the rate in their younger group $(69 \%, p=0.01)$ with stage I NSCLC [12]. Nonetheless, generally speaking, chronological age itself is still considered a major risk factor in long-term follow-up. In a study based on SEER conducted by Mery et al. [17] and retrospective matched study by Goodgame et al. [18], both authors reported worse overall survival for elderly patients.

Few studies have examined the association between lung cancer recurrence and age. Maeda et al. analyzed risk factors for the recurrence of stage I NSCLC; finding that old age ( $\geq 65$ years) was a risk factor with borderline significance for cancer recurrence in a multivariate analysis $(p=$ 0.051) [19]. In contrast, Goodgame and colleagues reported that cancer recurrence rate in elderly patients was the same as that in younger patients (3-year cumulative

Table 3 Short- and long-term outcomes of stage I non-small cell lung cancer

\begin{tabular}{llll}
\hline & Elderly group $(n=285)$ & Younger group $(n=1055)$ & $p$ \\
\hline Short-term results & $6(2.2)$ & & $0.014^{*}$ \\
30-day mortality, $n(\%)$ & $11(3.9)$ & $5(0.5)$ & $<0.001^{*}$ \\
90-day mortality, $n(\%)$ & 47.7 & 26.9 & $<0.001^{*}$ \\
Complication rate, \% & $11.2 \pm 12.2$ & $8.0 \pm 8.5$ & $<0.001^{* *}$ \\
Hospital stay, days & & & $<0.001^{* * *}$ \\
Long-term results & 69.0 & 81.1 & $<0.001^{* *}$ \\
5-year overall survival rate, \% & 53.3 & 80.2 & $<0.001^{*}$ \\
5-year disease-free survival rate, \% & 13.7 & 5.7 & \\
Recurrence rate within 2 years, \% & & \\
\hline
\end{tabular}

${ }^{*} p$ value estimated by Pearson's chi-square test: ${ }^{* *} p$ value estimated by Student's $t$ test $2 ;{ }^{* * *} p$ value estimated by the log-rank test 
Table 4 Multivariate analyses of risk and prognostic factors for short- and long-term results in elderly patients

\begin{tabular}{|c|c|c|c|}
\hline & Predictive factors & OR/HR (95\% Cl) & $p$ \\
\hline \multicolumn{4}{|l|}{ Short-term outcomes } \\
\hline 30-day mortality & DLCO less than $70 \%$ of prediction & $17.1(1.46-199)$ & 0.024 \\
\hline 90-day mortality & DLCO less than $70 \%$ of prediction & $8.47(1.11-64.6)$ & 0.039 \\
\hline \multirow[t]{2}{*}{ Complication rate } & Male gender & $7.80(3.10-19.6)$ & $<0.001$ \\
\hline & DLCO less than $70 \%$ of prediction & $3.51(1.03-12.0)$ & 0.045 \\
\hline \multirow[t]{2}{*}{ Hospital stay } & Open thoracotomy & $6.75(2.41-11.1)$ & 0.003 \\
\hline & DLCO less than $70 \%$ of prediction & $8.64(1.88-15.4)$ & 0.013 \\
\hline \multicolumn{4}{|l|}{ Long-term outcomes } \\
\hline \multirow[t]{2}{*}{ 5-year overall survival } & Squamous cell carcinoma & $3.18(1.56-6.48)$ & 0.001 \\
\hline & DLCO less than $70 \%$ of prediction & $2.37(1.10-5.14)$ & 0.028 \\
\hline \multirow[t]{2}{*}{ 5-year disease-free survival } & Male gender & $2.57(1.29-5.09)$ & 0.007 \\
\hline & DLCO less than $70 \%$ of prediction & $2.07(1.07-4.00)$ & 0.030 \\
\hline Recurrence rate within 2 years & Stage IB & $1.7(1.04-2.75)$ & 0.035 \\
\hline
\end{tabular}

DLCO: expected diffusing capacity for carbon monoxide

OR: odd ratio from logistic regression model for short-term outcomes

HR: hazard ratio from Cox proportional hazard model for long-term outcomes

$95 \% \mathrm{Cl}: 95 \%$ confidential interval

recurrence rate; 19 vs. $20 \%, p=0.425$ ) [18]. In our study, the recurrence rate in elderly patients was significantly higher than in younger patients (recurrence rate within 2 years; 13.7 vs. $5.7 \%, p<0.001$ ). This finding suggests that lung cancer in elderly patients is not always less virulent. Another explanation for more frequent distant failure in elderly patients might be less aggressive mediastinal lymph node dissection. Recently, Wang et al. reported that elderly patients without radical mediastinal lymphadenectomy experienced more frequent distant relapse compared to those who did undergo the procedure [20]. However, as shown in this study with systemic lymph node dissection in any age group, the cancer-free survival in the elderly was lower than in the younger patients. Therefore, more frequent and meticulous follow-up should be needed in the elderly group.

In this study, early and long-term outcomes in elderly patients were worse than expected, and decreased DLCO was the common predictive factor for poor results both in early and long-term outcomes. The importance of DLCO has been recognized in many gerontologic studies. Yano et al. reported that old age ( $\geq 70$ years), pneumonectomy, and DLCO less than $70 \%$ of predicted significantly increased life-threatening morbidity after pulmonary resection for lung cancer [21]. Ferguson et al. studied patients who underwent surgery for lung cancer and showed that the incidence of postoperative complications doubled in case of low diffusion capacity (DLCO less than $80 \%$ of predicted) [22-24]. For long-term outcome, it is not fully understood whether low diffusion capacity affects prognosis. Ferguson et al., in their study mentioned above, reported that low $\mathrm{FEV}_{1}$ did not affect long-term prognosis, but DLCO less than $60 \%$ of predicted significantly worsened overall survival [24]. Another study reported that a DLCO less than $40 \%$ best predicted decreased survival from causes other than cancer within stage I lung cancers [25]. Therefore, surgery for elderly patients with low diffusion capacity may require extra caution or reconsideration of alternative treatments, including limited resection or radiotherapy [26-28]. In this study, patients with DLCO less than $80 \%$ or less than $60 \%$ showed significantly worse outcome in overall survival $(\mathrm{HR}=4.6, p<0.001$ and $\mathrm{HR}=17.9, p<0.001$, respectively). Overall survival according to DLCO is presented in Fig. 2. According to the results of this study, pulmonary resection for lung cancer in elderly patients

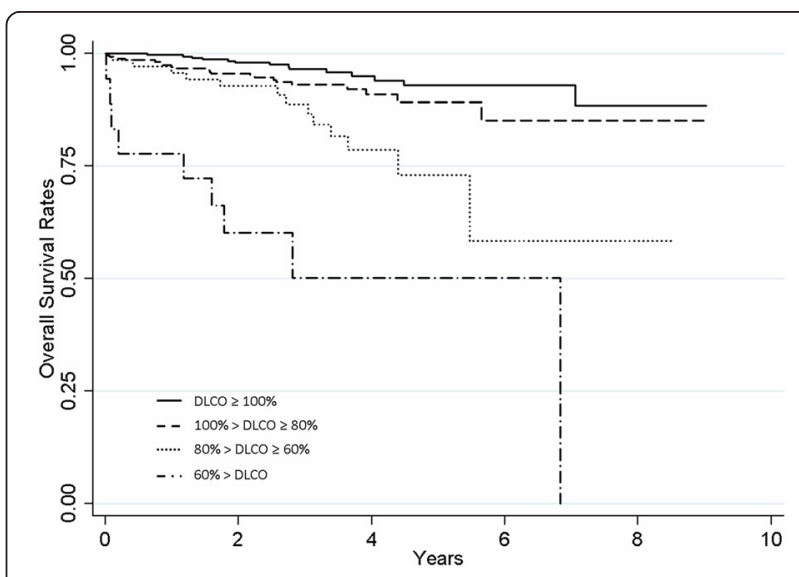

Fig. 2 Overall survival according to the level of diffusion capacity. Five-year overall survival rates in stage I lung cancer were significantly associated to the level diffusion capacity with hazard ratio of 0.11 (95\% $\mathrm{Cl}, 0.05-0.24)$ in the group with DLCO less than $80 \%$ and with hazard ratio of $0.06(95 \% \mathrm{Cl}, 0.02-0.13)$ in the group with DLCO less than $60 \%$ 
was far more risky than in younger patients. It is difficult to point out the risks of being old, but we presume that it comes from complex reasons, such as fragility to postsurgical stress and life expectancy of belonging society, and a searching analysis of the elderly patients are required in future studies. Until then, elderly patients who undergo pulmonary resection for lung cancer might require more rigorous application of operability than younger patients. Especially with the patients with decreased DLCO, additional assessments such as exercise pulmonary function test should be performed prior to surgery, and if the patients are judged to be unsuitable for surgery, alternative treatments should be considered. For patients who are medically inoperable for early lung cancer, stereotactic body radiation therapy (SBRT) has been widely applied and reported to be highly effective at controlling the primary tumor without serious toxicity. Radiation Therapy Oncology Group 0236 trial, which enrolled inoperable 59 patients with T1-2 lung cancer, showed 3-year survival of $55.8 \%$ after SBRT and high rates of local tumor control (3-year primary tumor control rate of $97.6 \%$.) [29]. Onishi et al. reported even better results, and the 5-year overall survival rates in this study showed 72 and $62 \%$ for stage IA and IB, respectively [30].

This study was a retrospective study and has associated limitations. Potential confounders affecting results after pulmonary resection in younger and elderly groups were minimized by matching clinicopathologic variables and surgical factors. Another limitation is that other known independent factors from previous studies, such as preoperative serum carcinoembryonic antigen level or lymphovascular invasion in pathologic reports, were not evaluated due to incomplete availability of these parameters in our database [31, 32]. Also, socioeconomic position of patients, which is also another important predictive factor in cancer treatment, was not considered in this study [33].

\section{Conclusions}

In conclusion, elderly patients with stage I NSCLC showed unsatisfying results in both short- and long-term outcomes. Especially, elderly patients with low DLCO are at risk for significantly worse outcome, indicating that patient selection should include assessment of pulmonary function, including DLCO, and also, more frequent following up should be needed.

\section{Abbreviations}

NSCLC: non-small cell lung cancer; $\mathrm{FEV}_{1}$ : forced expiratory volume in 1 second; FVC: forced vital capacity; DLCO: diffusing capacity for carbon monoxide; ARDS: acute respiratory distress syndrome; OR: odd ratio; HR: hazard ratio; IPF: interstitial pulmonary fibrosis; SEER: surveillance, epidemiology, and end results.

\section{Competing interests}

The authors declare that they have no competing interests.

\section{Authors' contributions}

JK provided the concept and design of this study. HKK, YSC, JIZ, and YMS have made a direct and substantial contribution to the work reported in the manuscript by providing materials, patients, or resources. BP and GL collected and analyzed the data, and BP wrote the article. All authors read and approved the final manuscript.

\section{Acknowledgements}

We thank all our colleagues and authors in the Department of Thoracic and Cardiovascular Surgery, Samsung Medical Center, for their assistance. There was no financial support in this study.

Received: 10 July 2015 Accepted: 30 December 2015

Published online: 19 January 2016

\section{References}

1. Siegel R, Naishadham D, Jemal A. Cancer statistics, 2013. CA Cancer J Clin. 2013;63:11-30.

2. Owonikoko TK, Ragin CC, Belani CP, Onton AB, Gooding WE, Taioli E, et al. Lung cancer in elderly patients: an analysis of the surveillance, epidemiology, and end results database. J Clin Oncol. 2007;25:5570-7.

3. Peake MD, Thompson S, Lowe D, Pearson MG. Ageism in the management of lung cancer. Age Ageing. 2003;32:171-7.

4. Wouters MW, Siesling S, Jansen-Landheer ML, Elferink MA, Belderbos J, Coebergh JW, et al. Variation in treatment and outcome in patients with non-small cell lung cancer by region, hospital type and volume in the Netherlands. Eur J Surg Oncol. 2010;36 Suppl 1:S83-92.

5. lyoda A, Hiroshima K, Moriya Y, Takiguchi Y, Sekine Y, Shibuya K, et al. Prospective study of adjuvant chemotherapy for pulmonary large cell neuroendocrine carcinoma. Ann Thorac Surg. 2006;82:1802-7.

6. Okami J, Higashiyama M, Asamura H, Goya T, Koshiishi Y, Sohara Y, et al. Pulmonary resection in patients aged 80 years or over with clinical stage I non-small cell lung cancer: prognostic factors for overall survival and risk factors for postoperative complications. J Thorac Oncol. 2009;4:1247-53.

7. Port JL, Kent M, Korst RJ, Lee PC, Levin MA, Flieder D, et al. Surgical resection for lung cancer in the octogenarian. Chest. 2004;126:733-8.

8. Ginsberg RJ, Rubinstein LV. Randomized trial of lobectomy versus limited resection for T1 N0 non-small cell lung cancer. Lung Cancer Study Group. Ann Thorac Surg. 1995;60:615-22. discussion 622-3.

9. Damhuis RA, Schutte PR. Resection rates and postoperative mortality in 7,899 patients with lung cancer. Eur Respir J. 1996;9:7-10.

10. Rostad H, Naalsund A, Strand TE, Jacobsen R, Talleraas O, Norstein J. Results of pulmonary resection for lung cancer in Norway, patients older than 70 years. Eur J Cardiothorac Surg. 2005;27:325-8.

11. Rivera C, Falcoz PE, Bernard A, Thomas PA, Dahan M. Surgical management and outcomes of elderly patients with early stage non-small cell lung cancer: a nested case-control study. Chest. 2011;140:874-80.

12. Cerfolio RJ, Bryant AS. Survival and outcomes of pulmonary resection for non-small cell lung cancer in the elderly: a nested case-control study. Ann Thorac Surg. 2006;82:424-9. discussion 429-30.

13. Rueth NM, Parsons HM, Habermann EB, Groth SS, Virnig BA, Tuttle TM, et al. The long-term impact of surgical complications after resection of stage I nonsmall cell lung cancer: a population-based survival analysis. Ann Surg. 2011;254:368-74.

14. Fried LP, Tangen CM, Walston J, Newman AB, Hirsch C, Gottdiener J, et al. Frailty in older adults: evidence for a phenotype. J Gerontol. 2001;56(3):146-56.

15. Partridge JS, Harari D, Dhesi JK. Frailty in the older surgical patient: a review. Age Ageing. 2012:41(2):142-7.

16. Sigel K, Bonomi M, Packer S, Wisnivesky J. Effect of age on survival of clinical stage I non-small-cell lung cancer. Ann Surg Oncol. 2009;16:1912-7.

17. Mery CM, Pappas AN, Bueno R, Colson Y, Linden P, Sugarbaker DJ, et al. Similar long-term survival of elderly patients with non-small cell lung cancer treated with lobectomy or wedge resection within the surveillance, epidemiology, and end results database. Chest. 2005;128:237-45.

18. Goodgame B, Viswanathan A, Zoole J, Gao F, Miller CR, Subramanian J, et al. Risk of recurrence of resected stage I non-small cell lung cancer in elderly patients as compared with younger patients. J Thorac Oncol. 2009;4:1370-4.

19. Maeda R, Yoshida J, Ishii G, Hishida T, Aokage K, Nishimura M, et al. Long-term survival and risk factors for recurrence in stage I non-small cell lung cancer patients with tumors up to $3 \mathrm{~cm}$ in maximum dimension. Chest. 2010;138:357-62. 
20. Wang Y, Wu N, Chen J, Lv C, Yan S, Li S, et al. Is radical mediastinal lymphadenectomy necessary for elderly patients with clinical $\mathrm{N}$-negative non-small-cell lung cancer? A single center matched-pair study. J Surg Res. 2015:193:435-41.

21. Yano T, Yokoyama H, Fukuyama Y, Takai E, Mizutani K, Ichinose Y. The current status of postoperative complications and risk factors after a pulmonary resection for primary lung cancer. A multivariate analysis. Eur J Cardiothorac Surg. 1997;11:445-9.

22. Ferguson MK, Dignam JJ, Siddique J, Vigneswaran WT, Celauro AD. Diffusing capacity predicts long-term survival after lung resection for cancer. Eur J Cardiothorac Surg. 2012;41:e81-6.

23. Ferguson MK, Little L, Rizzo L, Popovich KJ, Glonek GF, Leff A, et al. Diffusing capacity predicts morbidity and mortality after pulmonary resection. J Thorac Cardiovasc Surg. 1988;96:894-900.

24. Ferguson MK, Watson S, Johnson E, Vigneswaran WT. Predicted postoperative lung function is associated with all-cause long-term mortality after major lung resection for cancer. Eur J Cardiothorac Surg. 2014:45:660-4.

25. Liptay MJ, Basu S, Hoaglin MC, Freedman N, Faber LP, Warren WH, et al. Diffusion lung capacity for carbon monoxide (DLCO) is an independent prognostic factor for long-term survival after curative lung resection for cancer. J Surg Oncol. 2009;100:703-7.

26. Keenan RJ, Landreneau RJ, Maley Jr RH, Singh D, Macherey R, Bartley S, et al. Segmental resection spares pulmonary function in patients with stage I lung cancer. Ann Thorac Surg. 2004;78:228-33. discussion 228-33.

27. Fukumoto S, Shirato H, Shimzu S, Ogura R, Kitamura K, Yamazaki K, et al. Small-volume image-guided radiotherapy using hypofractionated, coplanar, and noncoplanar multiple fields for patients with inoperable stage I nonsmall cell lung carcinomas. Cancer. 2002;95:1546-53.

28. Crabtree T, Puri V, Timmerman R, Fernando H, Bradley J, Decker PA, et al. Treatment of stage I lung cancer in high-risk and inoperable patients: comparison of prospective clinical trials using stereotactic body radiotherapy (RTOG 0236), sublobar resection (ACOSOG Z4032), and radiofrequency ablation (ACOSOG Z4033). J Thorac Cardiovasc Surg. 2013; 145:692-9.

29. Timmerman R, Paulus R, Galvin J, Michalski J, Straube W, Bradley J, et al, Stereotactic body radiation therapy for inoperable early stage lung cancer. JAMA. 2010;303:1070-6.

30. Onishi H, Shirato H, Nagata Y, Hiraoka M, Fujino M, Gomi K, et al. Stereotactic body radiotherapy (SBRT) for operable stage I non-small-cell lung cancer: can SBRT be comparable to surgery? Int J Radiat Oncol Biol Phys. 2011:81(5):1352-8.

31. Kuo SW, Chen JS, Huang PM, Hsu HH, Lai HS, Lee JM. Prognostic significance of histologic differentiation, carcinoembryonic antigen value, and lymphovascular invasion in stage I non-small cell lung cancer. J Thorac Cardiovasc Surg. 2014;148:1200-7.e3.

32. Mollberg NM, Bennette C, Howell E, Backhus L, Devine B, Ferguson MK. Lymphovascular invasion as a prognostic indicator in stage I non-small cell lung cancer: a systematic review and meta-analysis. Ann Thorac Surg. 2014; 97:965-71.

33. Woods LM, Rachet B, Coleman MP. Origins of socio-economic inequalities in cancer survival: a review. Ann Onc. 2006;17:5-19.

\section{Submit your next manuscript to BioMed Central and we will help you at every step:}

- We accept pre-submission inquiries

- Our selector tool helps you to find the most relevant journal

- We provide round the clock customer support

- Convenient online submission

- Thorough peer review

- Inclusion in PubMed and all major indexing services

- Maximum visibility for your research

Submit your manuscript at www.biomedcentral.com/submit 